\title{
Does dexmedetomidine reduce postoperative pain after laparoscopic cholecystectomy with multimodal analgesia?
}

\author{
Jung-Kyu Park ${ }^{1}$, Soon Ho Cheong ${ }^{1,2}$, Kun Moo Lee ${ }^{1}$, Se Hun Lim ${ }^{1}$, Jeong Han Lee ${ }^{1}$, Kwangrae Cho ${ }^{1}$, \\ Myoung-Hun Kim ${ }^{1}$, and Hyun-Tae Kim ${ }^{1}$ \\ ${ }^{1}$ Department of Anesthesiology and Pain Medicine, Busan Paik Hospital, College of Medicine, Inje University, ${ }^{2}$ Paik Institute for \\ Clinical Research, Inje University, Busan, Korea
}

Background: Pain after laparoscopy is multifactorial and different treatments have been proposed to provide pain relief. Multimodal analgesia is now recommended to prevent and treat post-laparoscopy pain. Dexmedetomidine, an $\alpha 2$ agonist, has well-known anesthetic and analgesic-sparing effects. We evaluated the analgesic effect of perioperative dexmedetomidine infusion during laparoscopic cholecystectomy with multimodal analgesia.

Methods: Forty- two patients aged 20 to 60 years old were allocated randomly into one of 2 groups ( $\mathrm{n}=21$, in each). All patients underwent laparoscopic cholecystectomy under multimodal analgesia. The patients in group $\mathrm{P}$ received dexmedetomidine $1 \mu \mathrm{g} / \mathrm{kg}$ during $10 \mathrm{~min}$ before induction and then $0.5 \mu \mathrm{g} / \mathrm{kg} / \mathrm{h}$ continuously until the removal of the gall bladder while the patients in the group $\mathrm{C}$ received saline by the same methods as group P. Total analgesic consumption and VAS score were recorded for the first $24 \mathrm{hr}$.

Results: There were no significant differences in VAS scores between group P and group C during $24 \mathrm{hr}$ after laparoscopic cholecystectomy. VAS scores of group P were lower than that of group C during the 1st hr after operation. The amount of ketorolac required during the $24 \mathrm{hr}$ after the operation was significantly less in group $\mathrm{P}$ compared to group C.

Conclusions: The administration of dexmedetomidine during laparoscopic cholecystectomy with multimodal analgesia has minimal benefits on the reduction of the postoperative pain score. The amount of ketorolac requirements during $24 \mathrm{hr}$ after the operation showed significant difference. Dexmedetomidine might be helpful for the postoperative pain after laparoscopic cholecystectomy with multimodal analgesia. (Korean J Anesthesiol 2012; 63: 436-440)

Key Words: Dexmedetomidine, Laparoscopic cholecystectomy, Postoperative pain.

Received: February 24, 2012. Revised: 1st, March 28, 2012; 2nd, April 20, 2012; 3rd, May 8, 2012. Accepted: May 17, 2012.

Corresponding author: Se Hun Lim, M.D., Department of Anesthesiology and Pain Medicine, Busan Paik Hospital, College of Medicine, Inje University, Gaegeum 2-dong, Busanjin-gu, Busan 614-735, Korea . Tel: 82-51-890-6520, Fax: 82-51-898-4216, E-mail: anespc@medimail.co.kr (c) This is an open-access article distributed under the terms of the Creative Commons Attribution Non-Commercial License (http:// creativecommons.org/licenses/by-nc/3.0/), which permits unrestricted non-commercial use, distribution, and reproduction in any medium, provided the original work is properly cited. 


\section{Introduction}

Laparoscopic cholecystectomy (LC) resulted in less postoperative pain and reduction in the need for analgesics, as compared with open cholecystectomy [1]. Although pain after LC is less intense than that after open cholecystectomy, some patients still experience considerable discomfort during the first $24 \mathrm{~h}$ postoperative.

Pain after laparoscopy is multifactorial and different treatments have been proposed to provide pain relief [2]. Multimodal analgesia is now recommended to prevent and treat post-laparoscopy pain [3]. In this study, multimodal analgesia consisted of incisional local anesthetics, NSAID, dexamethasone, removing residual carbon dioxide, and postoperative opioid. We reported that such multimodal analgesic methods were effective for post-laparoscopic pain control [4].

Dexmedetomidine is a highly selective $\alpha_{2}$ adrenoceptor agonist that provides sedation, analgesia, and sympatholysis. These characteristics make dexmedetomidine useful anesthetic adjunct during operation. Previous studies report that intravenous has a definitive role in postoperative analgesia through the reduction of opioid consumption [5]. The analgesic property of dexmedetomidine is less effective than that of opioid, with the clinical implication that dexmedetomidine could not replace the use of opioids [6]. However, dexmedetomidine might play a part in multimodal analgesia and be able to reduce pain scores through synergistic mechanisms via the alpha-2 adrenergic pathways.

We investigated whether the addition of dexmedetomidine in the multimodal analgesic regimen reduces pain scores after laparoscopic cholecystectomy.

\section{Materials and Methods}

After the approval of the Institutional Review Board of our hospital, written informed consents were obtained from all patients participating in this study. A total of 42 patients meeting the criteria of the American Society of Anesthesiologists physical status I and II patients, aged 18-60 years, and who were undergoing elective laparoscopic cholecystectomy under general anesthesia were included in the study. The exclusion criteria included the following: a body mass index exceeding 30 $\mathrm{kg} / \mathrm{m}^{2}$, allergy to any medications, renal or hepatic insufficiency, neurological or psychiatric diseases, preoperative heart rate $<45$ beats/min, antihypertensive medication with clonidine or other $\alpha_{2}$ adrenergic agonist.

Patients were randomly allocated to the saline (group C) or to the dexmedetomidine group (group $\mathrm{P}$ ). There were no significant differences in sex ratio, age, weight, height, and duration of surgery and anesthesia between groups (Table 1).
All patients were premedicated with $0.2 \mathrm{mg}$ of glycopyrrolate by intramuscular injection, 1 hour before surgery.

On arrival at the operating room, standard monitoring was established and baseline values of heart rate, blood pressure, oxygen saturation and bispectral index (BIS) were recorded. Before induction, dexmedetomidine (Precedex ${ }^{\circledR}$, Hospira, USA) $1 \mu \mathrm{g} / \mathrm{kg}$ was infused for $10 \mathrm{~min}$ and then $0.5 \mu \mathrm{g} / \mathrm{kg} / \mathrm{h}$ continuously to group $\mathrm{P}$ until the removal of the gall bladder, while group $\mathrm{C}$ received saline by the same methods as group $\mathrm{P}$. The values of heart rate, systolic and diastolic pressure, oxygen saturation and BIS were recorded every $5 \mathrm{~min}$ after the infusion of dexmedetomidine and just before induction. If heart rate was less than 40 beats $/ \mathrm{min}$, atropine $0.5 \mathrm{mg}$ was administered to the patients. If systolic blood pressure was less than $80 \mathrm{mmHg}$, then ephedrine 10-20 mg was administered to the patients.

General anesthesia was induced with propofol $1.0 \mathrm{mg} /$ $\mathrm{kg}$ initially and $10 \mathrm{mg}$ of propofol was given every $30 \mathrm{sec}$ until the absence of eye-opening in response to verbal command and a BIS score under 60 . Rocuronium $0.6 \mathrm{mg} / \mathrm{kg}$ was given intravenously to facilitate tracheal intubation. Anesthesia was maintained with $50 \%$ inspired nitrous oxide combined with sevoflurane at an end-tidal concentration adjusted to maintain BIS values between 40 and 60 , and the heart rate and systolic blood pressure within $\pm 20 \%$ of respective baseline values. The patients were ventilated with $50 \%$ oxygen keeping the end tidal concentration of carbon dioxide at $35 \pm 5 \mathrm{mmHg}$. After the induction of anesthesia, $30 \mathrm{mg}$ of ketorolac, and $8 \mathrm{mg}$ of dexamethasone were intravenously administered for the postoperative pain control and for the prevention of nausea and vomiting.

All operations were performed by one surgeon who was highly experienced with the standard technique in LC. Before the creation of pneumoperitoneum, $0.25 \%$ bupivacaine $(3 \mathrm{ml})$ was infiltrated intracutaneously and subcutaneously at each

Table 1. Demographic Data

\begin{tabular}{lcc}
\hline & Group P (n=21) & Group C (n=21) \\
\hline ASA status (I/II) & $15 / 5$ & $14 / 6$ \\
Age (yr) & $42.1 \pm 10.3$ & $43.7 \pm 14.0$ \\
Sex (M/F) & $9 / 12$ & $10 / 11$ \\
Height (cm) & $164.2 \pm 6.4$ & $166.5 \pm 7.3$ \\
Weight (kg) & $63.1 \pm 11.6$ & $68.9 \pm 12.1$ \\
Duration of surgery (min) & $29 \pm 11.0$ & $29.5 \pm 14.0$ \\
Duration of anesthesia (min) & $61.8 \pm 13.7$ & $56.0 \pm 13.8$ \\
End-tidal concentration of & $1.26 \pm 0.5^{*}$ & $1.65 \pm 0.2$ \\
$\quad$ sevoflurane (\%) & &
\end{tabular}

Values are mean \pm SD or number of patients. There are no significant differences between the groups except in the end-tidal concentration of sevoflurane values. Group P: Dexmedetomidine infusion during perioperative period, Group C: normal saline infusion during perioperative period. ASA: American Society of anesthesiologists. ${ }^{*} \mathrm{P}<$ 0.05 compared with group $C$. 
trocar insertion site. Pneumoperitoneum was achieved with carbon dioxide, and intraperitoneal pressure was maintained below $12 \mathrm{mmHg}$ during surgery. At the end of operation, the carbon dioxide was carefully evacuated through the open trocars by manual compression and residual neuromuscular blockade was antagonized with neostigmine and glycopyrrolate. Patients were transferred to the PACU where blood pressure, pulse, and oxygen saturation were monitored by nurses who were blinded from the patient group assignment.

Before surgery, the patients were instructed to use a visual analogue scale (VAS: $0-10$, where $0=$ no pain, and $10=$ worst possible pain) for pain measurement and assessed at 15, 30 minutes, and at 1, 2, 4, 8, 12, and $24 \mathrm{~h}$ intervals after operation by an anesthesiologist who was not involved in the study. When the patient requested analgesics due to pain or the VAS was higher than 4, $30 \mathrm{mg}$ of ketorolac was IV injected first, and 30 minutes later if the VAS was still higher than 4, patients received intravenous tramadol (50 mg) boluses as weak opioid agonists. Thirty minutes after the administration of tramadol, if patients still complained of pain greater than VAS 4, $20 \mu \mathrm{g}$ intravenous fentanyl was given repeatedly until the VAS was less than 4 . Intravenous ondansetron $4 \mathrm{mg}$ was administered to the patients who were suffering from postoperative nausea and vomiting and was repeated if necessary. The patients, who satisfied the PACU discharge criteria, were discharged to the ward.

Sample size calculations were based on the previous study involving multimodal analgesic treatments after elective laparoscopic cholecystectomy [7]. We considered a reduction in the VAS of 2.0 as clinically significant. A priori, 21 patients were required as the minimum size for each group assuming

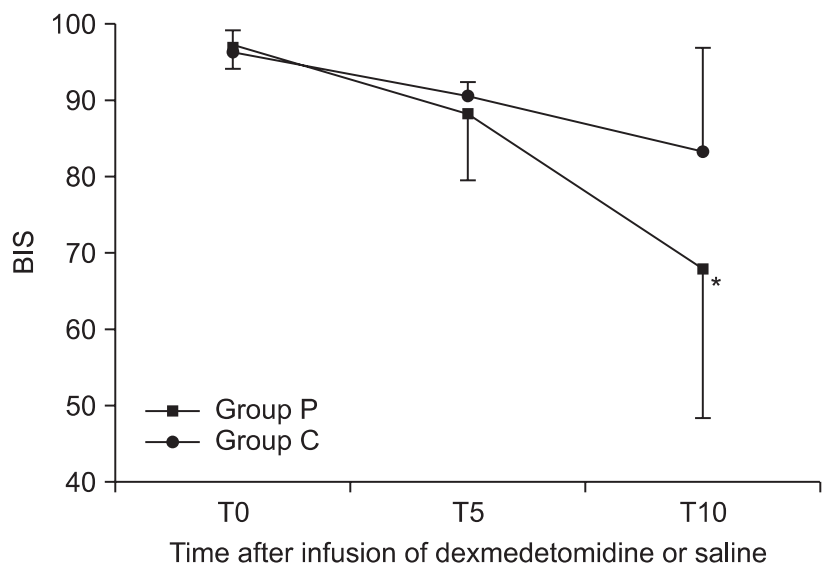

Fig. 1. Changes in BIS between groups during preoperative infusion of solution. The BIS values of group P decreased significantly compared to group $\mathrm{C}$ at $10 \mathrm{~min}$ after the infusion of the study solution. Group $\mathrm{P}$ : dexmedetomidine infusion during perioperative period, Group C: normal saline infusion during perioperative period. BIS: Bispectral index, T0, 5, 10: solution start time, 5 minutes after solution start, 10 min after solution start. $* \mathrm{P}<0.05$ compared with group $\mathrm{C}$. an $\alpha$ value of 0.05 and a power value of $80 \%$. All of the results were recorded with mean \pm standard deviation. Student's t-test was used to compare to the induction doses of propofol and the amount of ketorolac and tramadol given to patients between group P and group C. Repeated measures ANOVA was used for the comparison of dexmedetomidine effect on repeatedly measured VAS, BIS, heart rate, and blood pressure with time. Statistical analyses were performed using MedCalc for Windows, version 9.6 (MedCalc Software, Mariakerke, Belgium) and P values under 0.05 were considered statistically significant.

\section{Results}

The BIS values for group $\mathrm{P}$ decreased significantly compared to group $\mathrm{C}$ at $10 \mathrm{~min}$ after the infusion of the study solution (dexmedetomidine or saline) (Fig. 1).

The systolic blood pressure of group $\mathrm{P}$ decreased gradually during the infusion of the study solution. The decreases were not so severe that no patients need any vasopressors. There were no significant changes of blood pressure in the group $\mathrm{C}$ during the infusion of the study solution (Fig. 2).

The heart rate of group $\mathrm{P}$ decreased gradually during the infusion of the study solution (Fig. 3). There were less than 50 beats/min in 3 patients, but, no significant hemodynamic changes. There were significant differences in mean end tidal concentrations of sevoflurane during operation (Table 1). The doses of propofol for induction in group $\mathrm{P}$ patients were significantly less compared to those of group C (Table 2).

There were significant differences of VAS between group $\mathrm{P}$ and group $\mathrm{C}$ until 1 hour after laparoscopic cholecystectomy

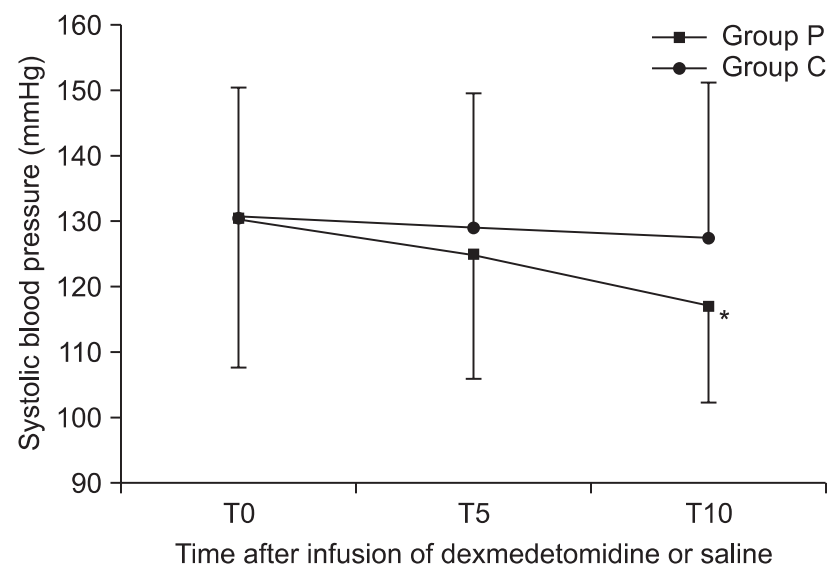

Fig. 2. Changes in systolic blood pressure between groups during preoperative infusion of solution. The systolic blood pressure of group $\mathrm{P}$ decreased gradually during the infusion of the study solution. Group P: dexmedetomidine infusion during perioperative period, Group C: normal saline infusion during perioperative period. T0, 5, 10: solution start time, 5 minutes after solution start, 10 minutes after solution start. ${ }^{*} \mathrm{P}<0.05$ compared with group $\mathrm{C}$. 


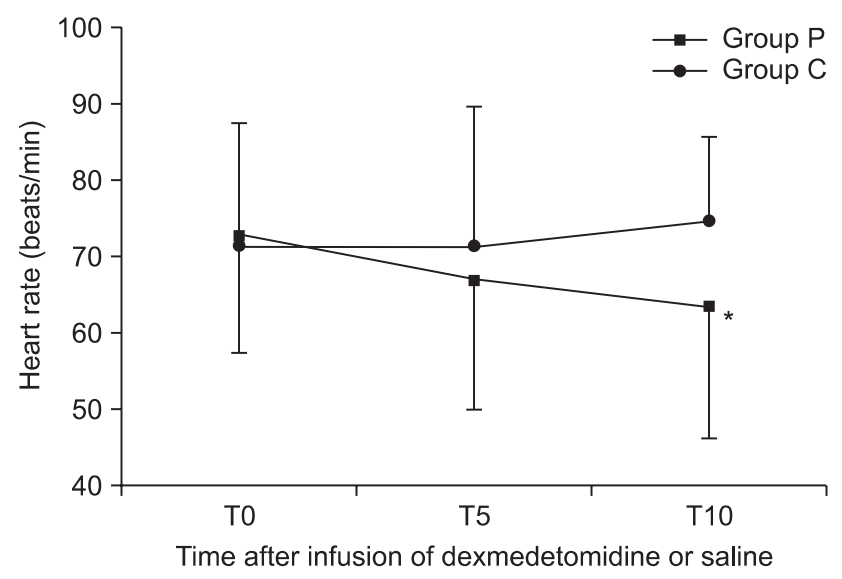

Fig. 3. Changes in heart rate between groups during preoperative infusion of solution. The heart rate of group P decreased gradually during the infusion of the study solution. Group P: dexmedetomidine infusion during perioperative period, Group C: normal saline infusion during perioperative period. T0, 5, 10: solution start time, 5 min after solution start, 10 min after solution start. ${ }^{*} \mathrm{P}<0.05$ compared with group C.

Table 2. Amount of Propofol for Induction and Perioperative Analgesic Consumptions

\begin{tabular}{lcr}
\hline & Group P & Group C \\
\hline Propofol (mg) & $83 \pm 23.4^{*}$ & $117 \pm 33.9$ \\
Ketorolac (mg) & $43.5 \pm 18^{\dagger}$ & $66 \pm 39.6$ \\
Tramadol (mg) & $30 \pm 41$ & $28 \pm 31.5$ \\
\hline
\end{tabular}

Values are mean \pm SD. Group P: Dexmedetomidine infusion during perioperative period, Group C: normal saline infusion during perioperative period. $* \mathrm{P}<0.01$ compared with group $\mathrm{C},{ }^{\dagger} \mathrm{P}<0.05$ compared with group $\mathrm{C}$.

with multimodal analgesia (Fig. 4).

The amount of ketorolac requirements during $24 \mathrm{~h}$ after the operation was significantly less in group P compared to group C (Table 2). None of the patients in group P needed opioid analgesics, but 2 patients in group $\mathrm{C}$ needed more potent opioid analgesics for pain control.

\section{Discussion}

Our study shows that dexmedetomidine significantly reduces pain scores after laparoscopic cholecystectomy with multimodal analgesia for 1 hour but, does not from $1 \mathrm{~h}$ to $24 \mathrm{~h}$ after the operation.

Postoperative pain in laparoscopy is caused by various reasons, therefore, to reduce it, multimodal treatments are suggested [8]. There is a report that giving local anesthetic [9], removing residual carbon dioxide [8], preemptive analgesia [10] and dexamethasone [3] are effective and recently multimodal

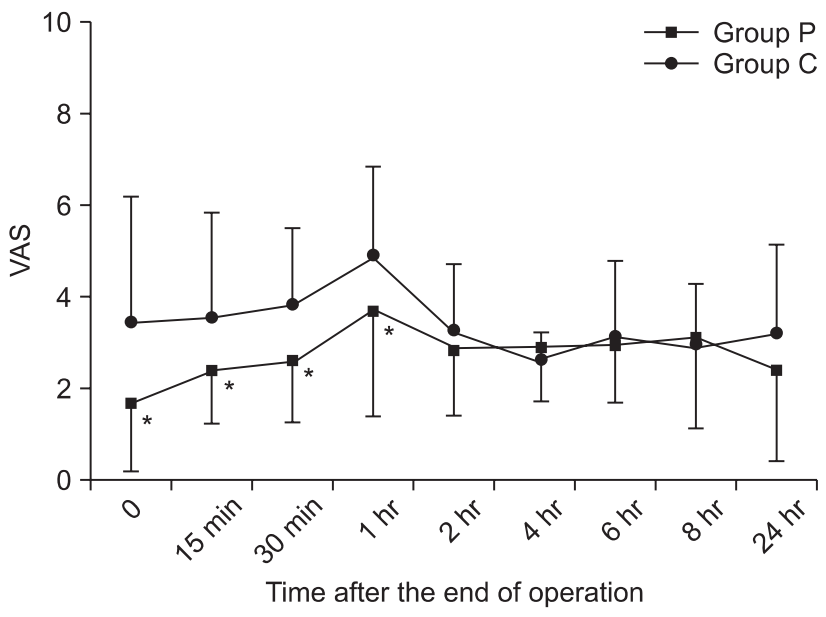

Fig. 4. Changes in postoperative pain between groups. Patients who received dexmedetomidine suffered less pain during 1 hour after laparoscopic cholecystectomy but, not after $1 \mathrm{~h}$ after the operation. Group P: dexmedetomidine infusion during perioperative period, Group C: normal saline infusion during perioperative period. VAS: Visual analogue scale. ${ }^{*} \mathrm{P}<0.05$ compared with group $\mathrm{C}$.

analgesia using all of methods written above is recommended because it is more effective [3]. We reported that such multimodal analgesic method was effective for postlaparoscopic pain control [4].

Dexmedetomidine is a potent and more selective $\alpha_{2}$ adrenoreceptor agonist than clonidine. Compared with clonidine, dexmedetomidine has an $\alpha_{2}: \alpha_{1}$ adrenoreceptor ratio of approximately $1,600: 1$ [11]. The alpha- 2 receptors are located on blood vessels, sympathetic terminals, and central nervous systems, which mediate vasoconstriction, inhibit norepinephrine release, and sedation, reduction of tonic levels of sympathetic outflow, and augmentation of cardiac-vagal activity, respectively [12].

Dexmedetomidine has sedative and analgesic sparing effects through $\alpha_{2}$ adrenoceptor in locus ceruleus [13]. It is an interesting sedative for not affecting the ventilator response to carbon dioxide [14]. Unlike other sedatives, it provides respiratory stability in that it does not cause ventilator depression [15]. The BIS values of group P decreased significantly compared to group $\mathrm{C}$ at $10 \mathrm{~min}$ after the infusion of dexmedetomidine. But, there was no clinically significant respiratory depression. Although there were no significant differences in VAS between group $\mathrm{P}$ and group $\mathrm{C}$ from 1 hour after the operation, the amounts of analgesic requirements showed statically significant differences. This result was consistent with other studies [16]. Ebert et al. [16] reported that sedation achieved by high plasma concentration recovered $4 \mathrm{~h}$ later after discontinuation of dexmedetomidine infusion. This might affect emergence causing extubation delay. As we stopped the infusion after the resection of gall bladder to least affect the recovery, there 
was no significant difference in extubation time between the 2 groups.

Dexmedetomidine has anesthetic sparing effects during induction and maintenance [17]. We found that the doses of propofol for induction in the patients of group $\mathrm{P}$ were significantly less compared to the doses required of group C. In addition, there were significant differences in the concentrations of inhalational agents between group $\mathrm{P}$ and group $\mathrm{C}$.

Dexmedetomidine can cause an increase in blood pressure and a decrease in heart rate with large concentrations or with rapid infusion rates [18]. Activation of $\alpha_{2}$ adrenoceptors on vascular smooth muscle is thought to result in vasoconstriction, increased blood pressure and probable reflex decreased heart rate [18]. In our study, there were decreases of both heart rates and blood pressure during the bolus infusions. This suggests that initial $1 \mu \mathrm{g} / \mathrm{kg}$ loading infusion for $10 \mathrm{~min}$ is not rapid and may not cause large blood concentrations of dexmedetomidine. More central effects, such as sedation, and a decrease in sympathetic outflow and circulating catecholamine might cause decreases in blood pressure and heart rate. Decreases in heart rate were not so severe enough to cause hemodynamic instability.

In this study, we found that the infusion of dexmedetomidine into multimodal analgesia regimen had minimal benefits on the postoperative pain scores after laparoscopic cholecycstectomy without any significant side effects. The amount of ketorolac requirements during 24 hours after the operation showed significant difference. Dexmedetomidine might be helpful for the postoperative pain after laparoscopic cholecystectomy with multimodal analgesia.

\section{Acknowledgments}

This work supported by the 2011 Inje University Research Grant.

\section{References}

1. Joris J, Cigarini I, Legrand M, Jacquet N, De Groote D, Franchimont $\mathrm{P}$, et al. Metabolic and respiratory changes after cholecystectomy performed via laparotomy or laparoscopy. Br J Anaesth 1992; 69: 341-5.

2. Wills VL, Hunt DR. Pain after laparoscopic cholecystectomy. Br J Surg 2000; 87: 273-84.

3. Bisgaard T. Analgesic treatment after laparoscopic cholecystectomy: a critical assessment of the evidence. Anesthesiology 2006;
104: 835-46.

4. Lim SH, Jang EH, Kim MH, Cho K, Lee JH, Lee KM, et al. Analgesic effect of preoperative versus intraoperative dexamethasone after laparoscopic cholecystectomy with multimodal analgesia. Korean J Anesthesiol 2011; 61: 315-9.

5. Tufanogullari B, White PF, Peixoto MP, Kianpour D, Lacour T, Griffin J, et al. Dexmedetomidine infusion during laparoscopic bariatric surgery: the effect on recovery outcome variables. Anesth Analg 2008; 106: 1741-8.

6. Cortinez LI, Hsu YW, Sum-Ping ST, Young C, Keifer JC, Macleod D, et al. Dexmedetomidine pharmacodynamics: Part II: Crossover comparison of the analgesic effect of dexmedetomidine and remifentanil in healthy volunteers. Anesthesiology 2004; 101: 1077-83.

7. Bucciero M, Ingelmo P, Fumagalli R, Noll E, Garbagnati A, Somaini $\mathrm{M}$, et al. Intraperitoneal ropivacaine nebulization for pain management after laparoscopic cholecystectomy: a comparison with intraperitoneal instillation. Anesth Analg 2011; 113: 1266-71.

8. Alexander JI. Pain after laparoscopy. Br J Anaesth 1997; 79: 369-78.

9. Lee IO, Kim SH, Kong MH, Lee MK, Kim NS, Choi YS, et al. Pain after laparoscopic cholecystectomy: the effect and timing of incisional and intraperitoneal bupivacaine. Can J Anaesth 2001; 48: 545-50.

10. Joshi GP, Viscusi ER, Gan TJ, Minkowitz H, Cippolle M, Schuller R, et al. Effective treatment of laparoscopic cholecystectomy pain with intravenous followed by oral COX-2 specific inhibitor. Anesth Analg 2004; 98: 336-42.

11. Kamibayashi T, Maze M. Clinical uses of alpha2-adrenergic agonists. Anesthesiology 2000; 93: 1345-9.

12. Muzi M, Goff DR, Kampine JP, Roerig DL, Ebert TJ. Clonidine reduces sympathetic activity but maintains baroreflex responses in normotensive humans. Anesthesiology 1992; 77: 864-71.

13. Guo TZ, Jiang JY, Buttermann AE, Maze M. Dexmedetomidine injection into the locus ceruleus produces antinociception. Anesthesiology 1996; 84: 873-81.

14. Hsu YW, Cortinez LI, Robertson KM, Keifer JC, Sum-Ping ST, Moretti EW, et al. Dexmedetomidine pharmacodynamics: Part I: crossover comparison of the respiratory effects of dexmedetomidine and remifentanil in healthy volunteers. Anesthesiology 2004; 101: 106676.

15. Belleville JP, Ward DS, Bloor BC, Maze M. Effects of intravenous dexmedetomidine in humans. I. Sedation, ventilation, and metabolic rate. Anesthesiology 1992; 77: 1125-33.

16. Ebert TJ, Hall JE, Barney JA, Uhrich TD, Colinco MD. The effects of increasing plasma concentrations of dexmedetomidine in humans. Anesthesiology 2000; 93: 382-94.

17. Jalonen J, Hynynen M, Kuitunen A, Heikkilä H, Perttilä J, Salmenperä $\mathrm{M}$, et al. Dexmedetomidine as an anesthetic adjunct in coronary artery bypass grafting. Anesthesiology 1997; 86: 331-45.

18. Bloor BC, Ward DS, Belleville JP, Maze M. Effects of intravenous dexmedetomidine in humans. II. hemodynamic changes. Anesthesiology 1992; 77: 1134-42. 